\title{
Statistical Analysis and Assessment of Wind Energy Potential in Sarajevo, Bosnia and Herzegovina
}

\author{
Rejhana BLAŽEVIĆ*, Halima HADŽIAHMETOVIĆ, Ismira AHMOVIĆ
}

\begin{abstract}
In this paper, wind energy potential in Sarajevo area, Bosnia and Herzegovina, was analyzed statistically. The analysis of wind energy potential was performed based on measured wind data in a one-year period from 1 January to 31 December 2019. Measured data were obtained on the basis of a meteorological station installed on the roof of the building of the Faculty of Mechanical Engineering in Sarajevo at $30 \mathrm{~m}$ height. Measured wind characteristics were statistically analyzed using the Weibull and Rayleigh distribution functions. The Weibull parameters were obtained using two methods, the energy pattern factor method and the maximum likelihood method, and both methods were used to find the Weibull parameters and the wind power density. The results of this investigation showed that the analyzed place falls under Class 1 of the international system of wind classification as the mean annual wind velocity recorded in the analyzed area was $1.215 \mathrm{~m} / \mathrm{s}$ and the corresponding annual mean power density was estimated to be $6.7 \mathrm{~W} / \mathrm{m}^{2}$ at $30 \mathrm{~m}$ height. The results show that the available wind energy potential to generate electricity in Sarajevo is low and wind power cannot be used to meet the energy needs in that region.
\end{abstract}

Keywords: Weibull and Rayleigh distribution; wind potential; wind power density; wind velocity

\section{INTRODUCTION}

The global energy demand is steadily increasing with the economic growth as well as population growth. According to the International Energy Agency statistics, global energy consumption in 2018 increased at nearly twice the average rate of growth since 2010. Higher electricity demand was responsible for over half of the growth in energy needs [1].

This increasing demand can be provided by new and renewable energy sources that are considered as sustainable clean energy sources. Renewable energy sources have many advantages over conventional energy sources used for many years. These advantages are that these energy sources do not pollute the environment, they are obtained from nature and most importantly, cannot be exhausted over time. Renewable energy sources, also, provide an opportunity to promote sustainable development and thus reduce dependence on the fossil fuel-based energy [2]. However, measuring the data of interest over a number of years is required to assess the utilization of renewable energy in specific periods. Wind energy is one of the fastest growing renewable energy sources in the world because of its many advantages. It is one of the zero emission energy sources and, also, one of the most widely used alternative sources [3].

A number of articles have been published on wind resource assessment and statistical analysis of wind velocity data [4-12]. When assessing the wind potential of a location, in addition to wind velocity data, it is necessary to know the frequency of occurrence of wind velocity, or wind velocity probability distribution. Many methods are used in the literature for the evaluation of the wind velocity distribution. However, the Rayleigh distribution and the Weibull distribution are the most commonly used probability density functions in the analysis of wind velocities records, and are specifically used for studies focused on wind energy evaluation [4-18]. Also, various methods for calculating the parameters of the Weibull wind velocity distribution for wind energy analysis are used [1923]. Fyrippis et. al [18] investigated wind power potential of a remote location in the northeastern part of Naxos
Island, Greece, using real data collected from a measurement mast. The obtained wind characteristics were statistically analyzed using the Weibull and Rayleigh distribution functions. Also, Parajuli [24] in his investigation analyzed the wind velocity and power density based on Weibull and Rayleigh models of Jumla, Nepal. In this study, daily mean wind velocity data for 10 years of the period were analyzed.

Furthermore, Azad et. al used Weibull distribution for statistical analysis of wind velocity data to find out the characteristics of wind energy conversion on Hatiya Island in Bangladesh. Two important parameters like Weibull shape factor and Weibull scale factor have been calculated by four methods [25]. Azad et al. [26] used three different Weibull distribution methods to find Weibull parameters and verified them using different widely accepted statistical tools. Usta developed and proposed an innovative method, PWMBP (probability weighted moments based on the power density method), for estimating the Weibull parameters in wind energy applications [27].

Mert and Karakus [28] investigated the wind characteristics of Antakya area in Hatay province and analyzed them statistically. Performances of the probability models were compared to the measured monthly and yearly wind velocity values. Satwika at. al [29] conducted a similar analysis for Bali, Indonesia to evaluate performance of wind turbine installation. Dahbi et al. [4] used the Weibull density function to estimate the monthly power wind density and to determine the characteristic of monthly parameters of Weibull. A simulation model was established to describe the characteristic of particular wind turbine. In the many studies, wind velocities were assumed to be distributed by Weibull without any investigation of the fitness. Yilmaz et al. [30] proposed an approach including statistical goodness of fit tests for research process of this fitness. They compared ten candidate distributions for the goodness of fit tests. As the result of the comparison, Weibull has been determined to be the best distribution representing wind data. 
In terms of statistical analysis and modelling, wind velocity and wind energy studies are very limited in Sarajevo [30, 31]. Therefore, the aim of this paper is to determine the wind energy potential in Sarajevo through the use of Weibull and Rayleigh statistical distributions. The measured data were obtained using the measurement and data acquisition system mounted on the roof of the Faculty of Mechanical Engineering in Sarajevo at $30 \mathrm{~m}$ height. Statistical analysis of analyzed region is performed by determining the frequencies and probabilities with the measured data.

\section{DESCRIPTION OF METEOROLOGICAL STATION FOR DATA ACQUISITION}

The meteorological station was installed in November 2018 on the roof of the Faculty of Mechanical Engineering in Sarajevo at the height of 30 meters, Fig. 1. It consists of a Data Logger, GPRS modem, temperature and humidity sensors, sensor for wind velocity and direction, atmospheric pressure sensors, MET controller, and UV and solar radiation sensors.

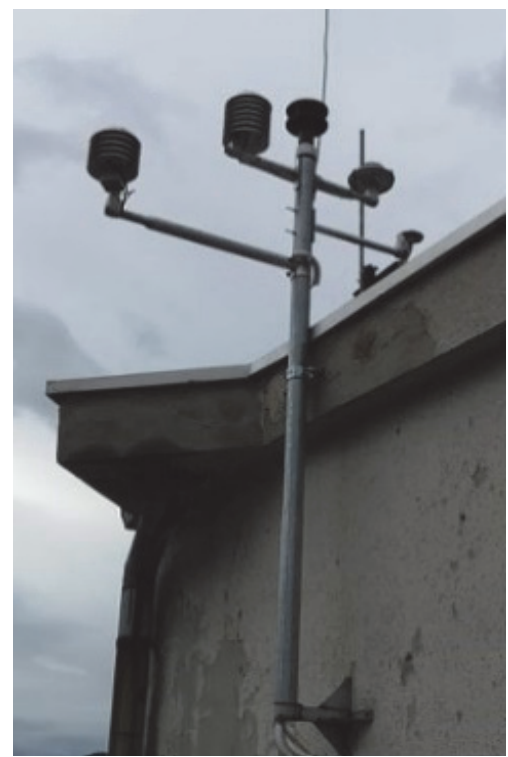

Figure 1 Meteorological station at the Faculty of Mechanical Engineering Sarajevo

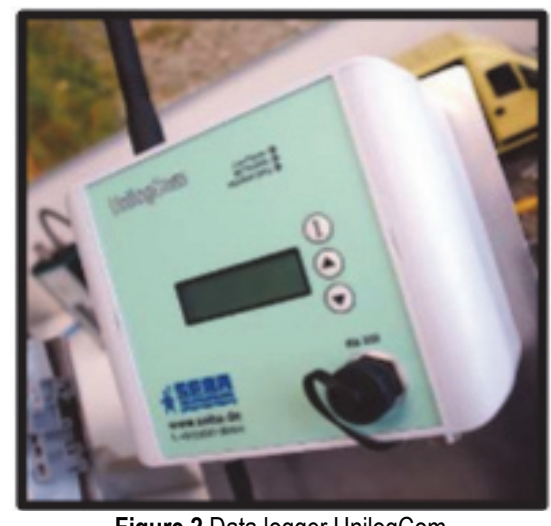

Figure 2 Data logger UnilogCom

Data obtained from all the installed instruments was acquired using a data logger which is presented in Fig. 2. The data logger, which was connected with all the available sensors on the meteorological station, recorded and stored the collected data in time - series format. Once the required data was stored, the transferring of the data for processing was achieved via a GSM method used by the data logger, Fig. 3.

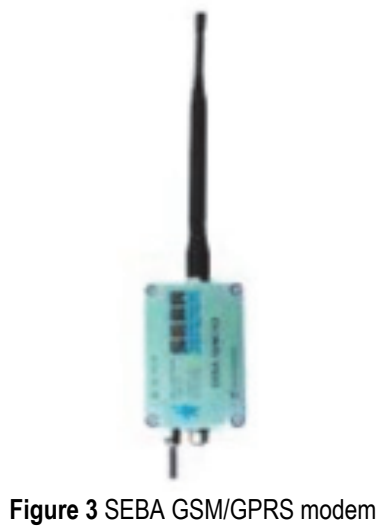

The measured data used to analyze the wind energy potential in this paper refer to a one-year measurement period from 1 January to 31 December 2020. The analysis of the measurement data concluded that the measurement data are of good quality. Wind velocity and direction measuring equipment were available $100 \%$ of the time during the analyzed period. The rate of the data recording was 48 per day in 30 minutes time intervals.

\section{STATISTICAL MODEL FOR WIND DATA ANALYSIS}

Wind velocity for a specific location can be characterized by several probability density functions. These functions illustrate how often the wind blows at certain wind velocity. For wind data analysis, the Weibull and Rayleigh probability density functions are commonly used and widely adopted [4-18]. In this paper, the Weibull and Rayleigh probability density functions are used to describe the wind velocity frequency distribution.

\subsection{Weibull Probability Density Function}

Weibull's distribution gives the probability of a certain wind velocity occurring over a period of time. The Weibull shape factor $(k)$ and scale factor $(c)$ are the main variables to express Weibull probability density function. These two parameters can determine the optimum performance of the wind energy conversion system [19-23]. The general form of the two-parameter Weibull probability density function is mathematically expressed by (1) [4-18]:

$f(v)=\frac{k}{c}\left(\frac{v}{c}\right)^{k-1} \mathrm{e}^{-\left(\frac{v}{c}\right)^{k}}$

where $f(v)$ is the probability of having a wind velocity of $v(\mathrm{~m} / \mathrm{s}), k>0$ is the dimensionless shape factor, and $c>0$ is the Weibull scale factor with units of velocity $(\mathrm{m} / \mathrm{s})$, which could be related to the average wind velocity through the shape factor, $k$, which describes the distribution of the wind velocity.

The cumulative distribution function is the area under the curve for the probability density function. The 
corresponding cumulative probability function of the Weibull distribution is given by Eq. (2):

$F(v)=1-\mathrm{e}^{-\left(\frac{v}{c}\right)^{k}}$

The parameters of the Weibull distribution can be calculated using various methods. There are several methods available in the literature to determine these two factors such as least square method, maximum likelihood method, the energy pattern factor method, moments method etc.

In this paper, the energy pattern factor method and the maximum likelihood method are used to fit a Weibull distribution to a measured wind velocity distribution, and to calculate the shape and scale parameters.

\subsubsection{Energy Pattern Factor Method}

This method is also known as the power density method. It has simpler formulation, easier implementation and also requires less computation. In this method, the ratio of the mean of the cubic wind velocity and the cubic of the mean wind velocity is the energy pattern factor.

To find the parameters $k$ and $c$, the first thing to find is the energy pattern factor from Eq. (3) [20, 21, 26]:

$$
E_{\mathrm{pf}}=\frac{\left(v^{3}\right)_{m}}{\left(v_{m}\right)^{3}}=\frac{\Gamma\left(1+\frac{3}{k}\right)}{\Gamma\left(1+\frac{1}{k}\right)^{3}}
$$

where $\left(v^{3}\right)_{m}$ represents the mean of the cube of wind velocity and $\left(v_{m}\right)^{3}$ represents the cube of the mean wind velocity. After calculating energy pattern factor, $k$ and $c$ can be determined by Eqs. (4) and (5) [20, 21, 26]:

$$
\begin{aligned}
& k=1+\frac{3.69}{E_{\mathrm{pf}}{ }^{2}} \\
& c=\frac{v_{m}}{\Gamma\left(1+\frac{1}{k}\right)}
\end{aligned}
$$

\subsubsection{Maximum Likelihood Estimation Method}

The Maximum Likelihood Estimation (MLE) method is one of the most well-known statistical methods for estimating the parameters of a distribution. Costa Rocha et al. [23] and Stevens et al. [19] used the MLM method in their investigation for the estimation of parameters of the Weibull wind velocity distribution for wind energy utilization purposes. This method uses a large number of iterations to calculate the best fit for the Weibull scale and shape parameters. The following Equation is used to calculate, in an iterative form, the Weibull $k$ parameter [7, 21]:

$$
k=\left[\frac{\sum_{i=1}^{N} v_{i}^{k} \ln \left(v_{i}\right)}{\sum_{i=1}^{N} v_{i}^{k}}-\frac{\sum_{i=1}^{N} \ln \left(v_{i}\right)}{N}\right]^{-1}
$$

where $v_{i}$ is the wind velocity at time step $i$, and $N$ is the number of time steps.

Once the shape parameter $k$ has been defined, the Eq. (7) provides the value of the scale parameter $c[7,21]$ :

$c=\left(\frac{\sum_{i=1}^{N} v_{i}^{k}}{N}\right)^{\frac{1}{k}}$

Eqs. (6) and (7) give the Weibull parameters at actual height $30 \mathrm{~m}$. Since these parameters should be determined at the hub height of wind turbine (in our case $50 \mathrm{~m}$ ), so it can be extrapolated according to Eqs. (8) to (10) [7]:

$$
\begin{aligned}
& c_{2}=c_{1}\left(\frac{h_{2}}{h_{1}}\right)^{n} \\
& k_{2}=k_{1} \frac{1-0.0881 \cdot \ln \left(\frac{h_{1}}{h_{r}}\right)}{1-0.0881 \cdot \ln \left(\frac{h_{2}}{h_{r}}\right)}
\end{aligned}
$$

$$
n=\frac{0.37-0.0881 \cdot \ln c_{1}}{1-0.0881 \cdot \ln \left(\frac{h_{1}}{h_{r}}\right)}
$$

where $c_{1}$ and $k_{1}$ are Weibull parameters at anemometer height $h_{1}, c_{2}$ and $k_{2}$ are Weibull parameters at desired height $h_{2}, h_{r}$ is a reference height at $10 \mathrm{~m}$ and $n$ is power law exponent.

\subsection{Rayleigh Probability Density Function}

Rayleigh's distribution is a simplified case of the Weibull distribution in which the shape factor is taken as $k$ $=2$. Because of its simplicity, this distribution is widely used for wind energy modeling by many researchers. Probability density function of Rayleigh distribution function is calculated as shown in Eq. (11) [4-18]:

$$
f(v)=\frac{2 v}{c^{2}} \mathrm{e}^{-\left(\frac{v}{c}\right)^{2}}=\frac{\pi}{2}\left(\frac{v}{v_{m}^{2}}\right) \mathrm{e}^{-\frac{\pi}{4}\left(\frac{v}{v_{m}}\right)^{2}}
$$

The Rayleigh cumulative distribution function is given by Eq. (12) [4-18]:

$F(v)=1-\mathrm{e}^{-\left(\frac{v}{c}\right)^{2}}=1-\mathrm{e}^{-\frac{\pi}{4}\left(\frac{v}{v_{m}}\right)^{2}}$ 
Scale factor $c$ in the case of the Rayleigh probability density function can be calculated as follows [4-18]:

$c=\frac{2}{\sqrt{\pi}} \cdot v_{m} \cong 1.128 \cdot v_{m}$

This is the simplest wind velocity probability distribution to represent the wind potential since it requires only the knowledge of the mean wind velocity, $v_{m}$, as can be seen from Eqs. (11) and (12).

\section{MEAN WIND VELOCITY AND WIND DIRECTION ANALYSIS}

The basic characteristics of wind are wind velocity intensity, direction and frequency. To assess the wind potential at any point, it is necessary to accurately identify the frequency distribution of wind velocity. The mean wind velocity indicates that the windy area is suitable for generating electricity by wind power. For the available time series data, the mean wind velocity of the area is defined in Eq. (1). Thus, all mean wind velocity values (daily, monthly and annual) were calculated using Eq. (14) [28]:

$v_{m}=\frac{1}{N} \sum_{i=1}^{N} v_{i}$

where $v_{i}$ is current wind velocity or the wind velocity value at time $i$ and $N$ is the number of times wind velocity was measured.

The wind power density based on the Weibull probability density function, with known shape factor $k$ and scale factor $c$, can be calculated according to Eq. (15):

$v_{m}=c \Gamma\left(1+\frac{1}{k}\right)$

In this paper, the wind velocity data were collected at height $h_{1}=30 \mathrm{~m}$ (meteorological station height)which is different from the hub height. Therefore, it is necessary to determine the relationship among wind velocity $v_{\text {hub }}$ at hub height $h_{\text {hub }}$, the wind velocity $v_{1}$ at height $h_{1}$, and the surface roughness length $z_{0}$. The change in wind velocity with height can be calculated using the logarithmic law, power law or LBL (Lawrence Berkeley Laboratory) model wind profile [33].

In this paper, the logarithmic law was used for calculation of the change in wind velocity with height by Eq. (16) $[28,34]$ :

$$
v_{\text {hub }}=v_{1} \frac{\ln \left(\frac{h_{\text {hub }}}{z_{0}}\right)}{\ln \left(\frac{h_{1}}{z_{0}}\right)}
$$

where $v_{1}$ is the wind velocity as measured at the meteo station at a height of $h_{1}$ above the ground, $v_{\text {hub }}$ is the wind velocity at hub height at a height of $h_{\text {hub }}$ above the ground and $z_{0}$ is the terrain dependent roughness length.

Surface roughness length $z_{0}$ was assumed to be 1.6 since the meteorological station is located in an urban area [35].

\section{WIND POWER DENSITY ANALYSIS}

The wind resource available at a potential place is most often assessed by calculating the wind power density. The mean wind power density can be expressed with Eq. (17) $[24,28]:$

$$
\bar{P}=\frac{1}{2} \frac{1}{N} \sum_{i=1}^{N} \rho_{i} v_{i}^{3}
$$

where $\bar{P}$ represents the mean wind power density, $N$ is the number of times, $v_{i}$ is the wind velocity value at time $i, \rho_{i}$ is air density value at time $i$ and depends on altitude, air pressure. In this paper, the value of $\rho$ was $1.225 \mathrm{~kg} / \mathrm{m}^{3}$.

If a probability density function $f(v)$ is used to model the average power in the wind velocity, the average power density is given by Eq. (18):

$\bar{P}=\frac{1}{2} \rho \int_{0}^{\infty} v^{3} \cdot f(v) \mathrm{d} v$

Difference in the power presented by Eqs. (17) and (18) depends on goodness of fit, in terms of fitting the probability density function of the measured data.

If the shape factor $k$ and scale faktor $c$ of the corresponding Weibull probability density function are known, the mean wind power density at a location can be calculated according to Eq. (19) [24]:

$\bar{P}=\frac{1}{2} \rho c^{3} \Gamma\left(1+\frac{3}{k}\right)$

If wind distribution is assumed according to Rayleigh probability density function, then the mean wind power density can be easily calculated based on the knowledge of the mean wind velocity according to Eq. (20) [24]:

$$
\bar{P}=\frac{6}{\pi} \cdot \frac{1}{2} \rho\left(v_{m}\right)^{3}=\frac{6}{\pi} \cdot \frac{1}{2} \rho\left(c \sqrt{\frac{\pi}{4}}\right)^{3}
$$

\section{RESULTS AND DISCUSSION}

The determination of the wind potential of the selected place was made by analyzing in detail the wind characteristics, such as the wind velocity, the prevailing direction, their duration and availability, as well as the resulting power density. In Figs. 4 and 5, the monthly mean wind velocities are presented for both heights, $30 \mathrm{~m}$ and 50 $\mathrm{m}$, respectively.

As it can be seen from Fig. 4, the windiest months were March and November with the mean wind velocity reaching approximately $1.5 \mathrm{~m} / \mathrm{s}$ and $1.6 \mathrm{~m} / \mathrm{s}$, while the 
calmest month was October where the mean wind velocity was $0.86 \mathrm{~m} / \mathrm{s}$ at height $30 \mathrm{~m}$.

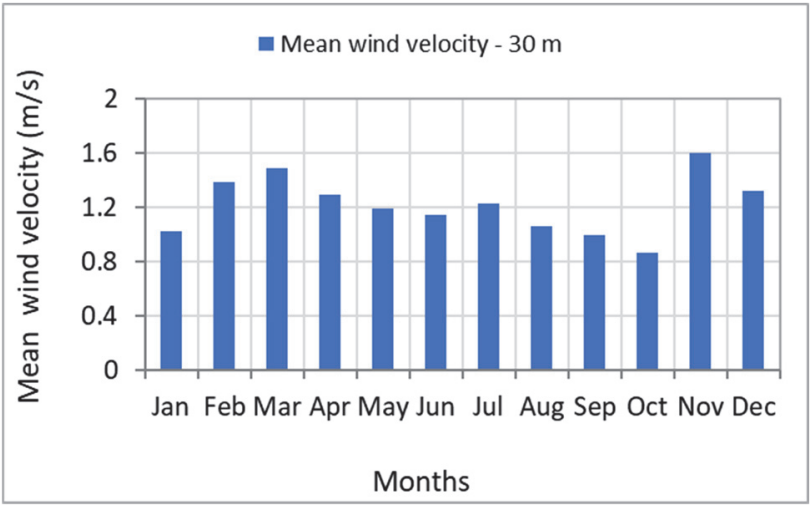

Figure 4 Monthly mean wind velocity at $30 \mathrm{~m}$ height

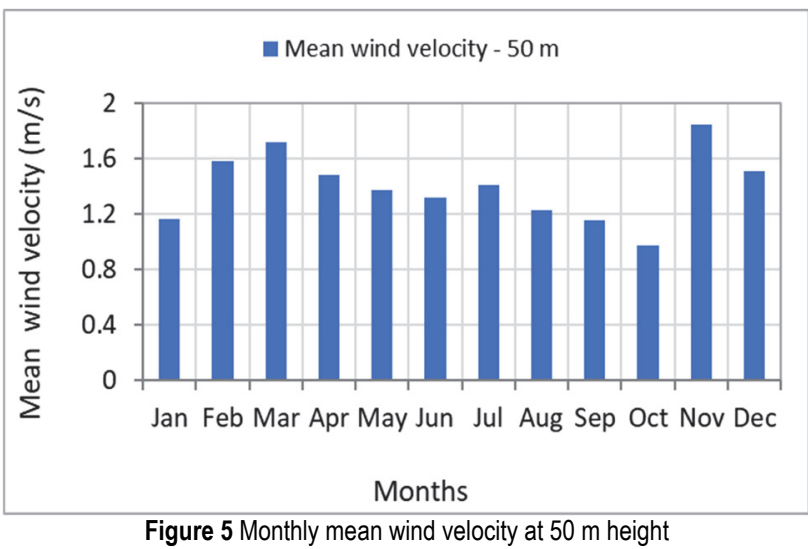

Using the data from this diagram, the corresponding annual mean velocity has been calculated to be about 1.21 $\mathrm{m} / \mathrm{s}$, indicating that the available wind energy potential is very low. By checking the wind velocity distribution in Fig. 4, it can be seen that the lowest values of wind velocity are in months with higher air temperature.

In addition to wind velocity, in wind data analysis, the prediction of the wind direction is also important, especially when planning the installation of a wind turbine or a wind farm. Wind rose shows the distributions of wind velocities, and the frequency of the varying wind directions, and can be drawn on the basis of meteorological observations of wind velocities and wind directions.

The annual wind rose based on time, is shown in Fig. 6. The prevailing wind blowing direction is $\mathrm{E}-\mathrm{W}$ and is conditioned by the basin morphology of the terrain.

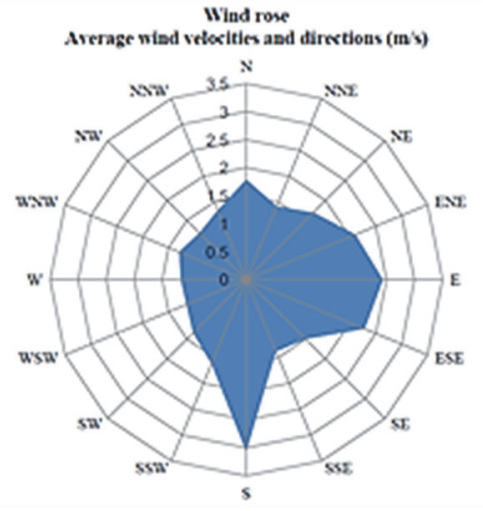

Figure 6 Annual wind rose for Sarajevo [31]
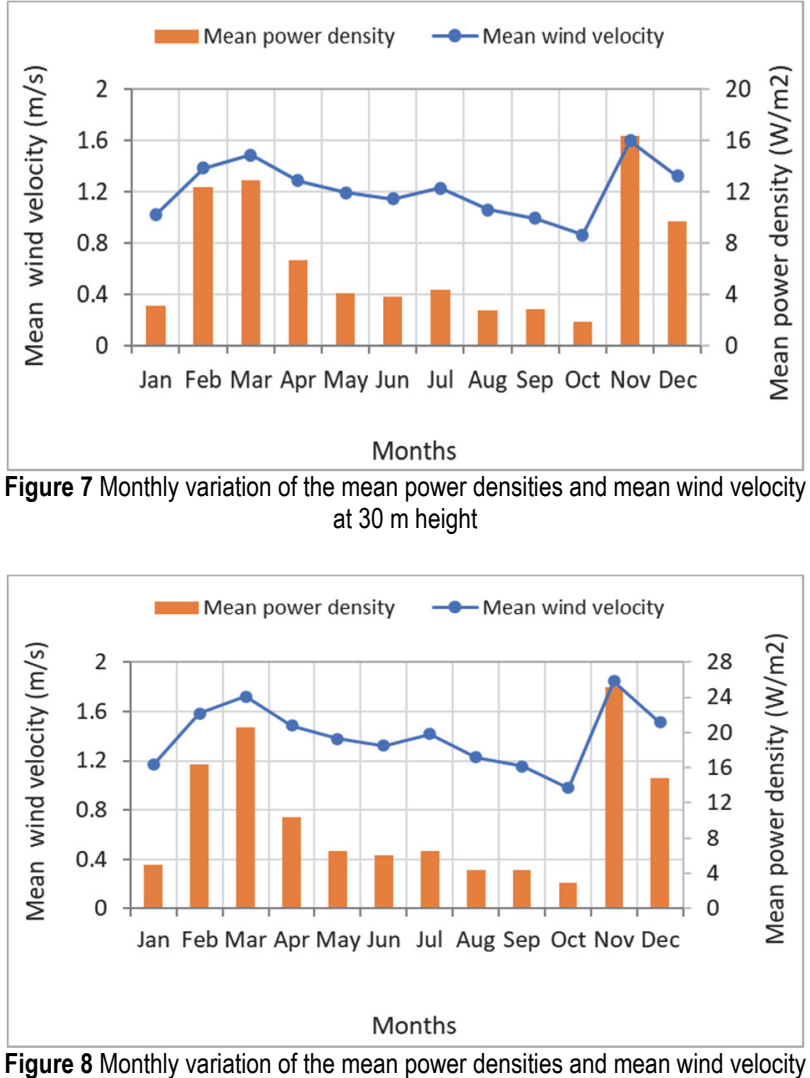

Figure 8 Monthly variation of the mean power
at $50 \mathrm{~m}$ height

The results of the wind velocity variation and the prevailing wind directions which characterized the location under consideration were further analyzed with respect to the corresponding mean wind power density. Wind velocity data measured over the one-year period were employed to estimate the wind power density in the Sarajevo area. Figs. 7 and 8 show the histograms of the monthly variations of the mean wind power densities.

As it can be seen from Figs. 7 and 8, the power densities calculated from the measured probability density distributions, show a large month to month variation. The minimum power density occurs in October and the highest power density value occurs in November.

Information on the average annual wind velocity is not sufficient to estimate the possible electricity production of a wind turbine. It is necessary to know how long the wind blows with a certain intensity. This information is provided by a wind velocity histogram. Fig. 9 shows a discrete histogram of wind velocities for the Sarajevo location, obtained on the basis of one-year wind velocity measurements at a height of $30 \mathrm{~m}$.

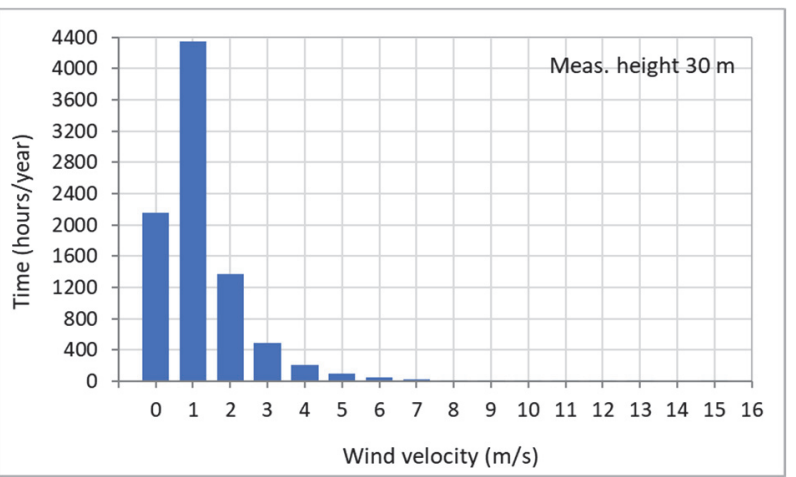

Figure 9 Discrete histogram of wind velocities 
The normalized discrete histogram of wind velocities can be described by some probability density distribution function.

In the literature about wind energy, several methods have been proposed to estimate wind energy potential. Statistical analysis usually uses Weibull and Rayleigh probability density distribution functions to describe the wind profile.

A comparison of Weibull and Rayleigh probability density functions with real data histogram is presented in Fig. 10. For the Weibull distribution, shape factor $k$ and scale factor $c$ were calculated using maximum likelihood estimation method and the energy pattern factor method.

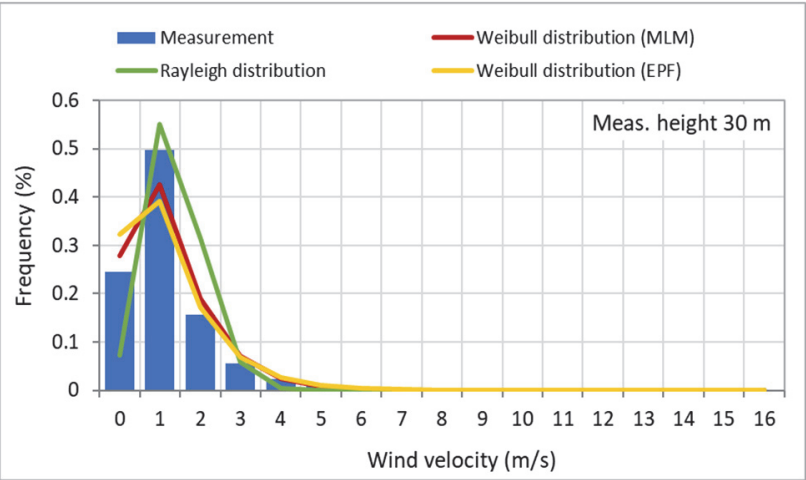

Figure 10 Probability density distribution of annual wind velocities

Fig. 10 shows Weibull and Rayleigh probability density functions fitted to the measured wind velocity values and it can be seen that the Weibull probability density function produces the best fit. The Weibull curves presented in Fig. 10 were obtained using two different methods for determination of the Weibull parameters. Fig. 10 shows the frequency with which the variable falls within different bins. It is clear that the wind velocity falls within the range of 0 to $1 \mathrm{~m} / \mathrm{s}$ about $25 \%$ of the time, 1 to $2 \mathrm{~m} / \mathrm{s}$ about $50 \%$ of the time, 2 to $3 \mathrm{~m} / \mathrm{s}$ about $15 \%$ of the time, 3 to $4 \mathrm{~m} / \mathrm{s}$ about $5 \%$ of the time, 4 to $5 \mathrm{~m} / \mathrm{s}$ about $2 \%$ of the time and so on.

Hence, it can be observed in Fig. 10 that the most frequent wind velocity expected in the area under investigation is the value between $1 \mathrm{~m} / \mathrm{s}$ and $2 \mathrm{~m} / \mathrm{s}$, a value which corresponds to the peak of the probability density function curve. This result is consistent with the results already obtained from the initial analysis of average wind velocity. Furthermore, this diagram shows that the wind velocity rarely exceeded the rated wind velocity corresponding to $4 \mathrm{~m} / \mathrm{s}$, and that the site never had wind velocities equal or greater than the cut-out velocity, $25 \mathrm{~m} / \mathrm{s}$, during the investigated time period. The previously mentioned remarks were further supported by the Weibull curve.
Furthermore, cumulative probability distribution of wind velocities is shown in Fig. 11, which indicates the fraction of time or probability that the wind velocity is equal or lower than $v$. The cumulative distribution function can also be used for estimating the time for which wind is within a certain velocity interval.

It can be seen from Fig. 11, that approximately $90 \%$ of the recorded wind velocities is below $2 \mathrm{~m} / \mathrm{s}$ and frequency for wind velocities greater than $2.5 \mathrm{~m} / \mathrm{s}$, cut-in wind velocity, is less than $10 \%$. From Fig. 11 can be seen, also, that the difference between the two models is relatively small, but though, Weibull represents the actual data better.

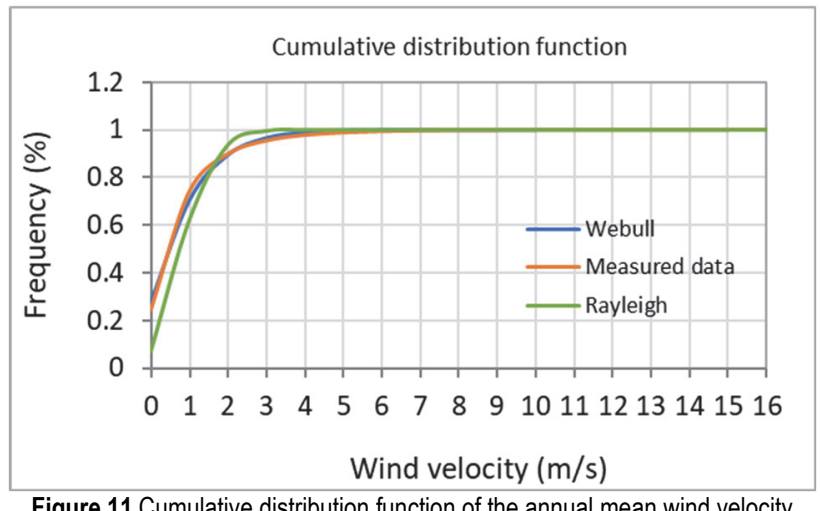

Figure 11 Cumulative distribution function of the annual mean wind velocity

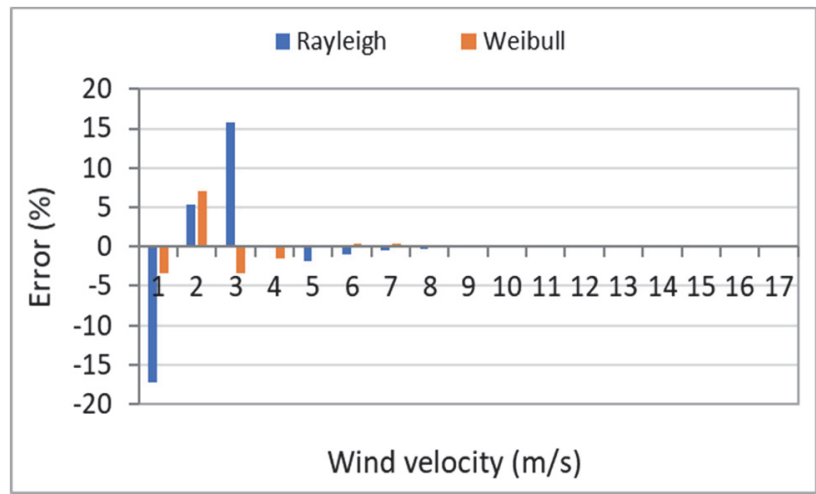

Figure 12 Error values in calculating the wind power density obtained from the Weibull and Rayleigh model in reference to the wind power density obtained from the measured data

Errors in calculating the power densities using the distribution of Weibull and Rayleigh model in comparison to those using the measured probability density distribution are presented in Fig. 12. For Weibull model the highest error value in the power density occurs for wind velocity of $2 \mathrm{~m} / \mathrm{s}$ with $7.05 \%$ and for Rayleigh model the highest error value in the power density occurs for wind velocity of 1 and $3 \mathrm{~m} / \mathrm{s}$ with $17 \%$.

Table 1 The Weibull parameters, $k$ and $c$, mean wind velocity and wind power density obtained using different methods

\begin{tabular}{|c|c|c|c|c|}
\hline Method & $k$ & $c / \mathrm{ms}^{-1}$ & $v_{m} / \mathrm{ms}^{-1}$ & Wind power density $/ \mathrm{Wm}^{-2}$ \\
\hline \multicolumn{5}{|c|}{ Height $30 \mathrm{~m}$} \\
\hline Measurement & - & - & 1.215 & 6.70 \\
\hline Maximum likelihood estimation method & 1.213 & 1.301 & 1.221 & 4.35 \\
\hline Energy pattern factor method & 1.094 & 1.246 & 1.204 & 5.19 \\
\hline \multicolumn{5}{|c|}{ Height $50 \mathrm{~m}$} \\
\hline Measurement & - & - & 1.4 & 10.2 \\
\hline Maximum likelihood estimation method & 1.208 & 1.509 & 1.417 & 6.86 \\
\hline Energy pattern factor method & 1.099 & 1.448 & 1.397 & 8.025 \\
\hline
\end{tabular}


Tab. 1. shows the Weibull parameters, $k$ and $c$, and mean wind velocity and wind power density obtained using two different methods of parameter estimation.

Based on the results obtained from the mean wind velocity and mean wind power density analysis, combined with the commercially international system of wind classification developed by Battelle - Pacific Northwest Laboratory, it was noted that the measurement site falls under Class 1. That indicates that the Sarajevo area is not suitable for electricity generation from wind energy. The average value of wind power density at actual height (30 $\mathrm{m})$ is $6.7 \mathrm{~W} / \mathrm{m}^{2}$, and there is no big difference for $50 \mathrm{~m}$ height, also, where wind power density is $10.2 \mathrm{~W} / \mathrm{m}^{2}$.

\section{CONCLUSION}

In this paper, wind power density and wind velocity distribution parameters in the Sarajevo area in Bosnia and Herzegovina were investigated using wind velocity data measured from $30 \mathrm{~m}$ height. The measured data used to analyze the wind energy potential in this paper refer to a one-year measurement period. For statistical analysis the Weibull and Rayleigh distributions were used.

Energy pattern factor method and maximum likelihood estimation method were used to determine Weibull parameters that described the characteristics of wind wave. Weibull parameters $k$ and $c$, using maximum likelihood estimation method, were found to be $1.21 \mathrm{~m} / \mathrm{s}$ and 1.51 $\mathrm{m} / \mathrm{s}$ for $30 \mathrm{~m}$ and $50 \mathrm{~m}$ height, respectively.

The seasonal wind velocity profile was drawn and mean wind velocity was found to be $1.2 \mathrm{~m} / \mathrm{s}$ at $30 \mathrm{~m}$ height and $1.4 \mathrm{~m} / \mathrm{s}$ at $50 \mathrm{~m}$ height. The highest mean power density value was $25.1 \mathrm{~W} / \mathrm{m}^{2}$ in November and the lowest average power density was $2.9 \mathrm{~W} / \mathrm{m}^{2}$ in October (at $50 \mathrm{~m}$ height). The mean annual wind power density was estimated to be $10.2 \mathrm{~W} / \mathrm{m}^{2}$.

All these results show that, overall, the potential to generate electricity from wind in Sarajevo region is very low and wind power cannot be used to meet the energy needs in that region. Therefore, due to low wind velocities, the construction of wind farms in the analyzed area is not recommended. In order to convert wind energy into the appropriate useful form of energy, its velocity should be between $3 \mathrm{~m} / \mathrm{s}$ and $12 \mathrm{~m} / \mathrm{s}$. In the analyzed area, the average wind velocity for each observed month, in a time period of one year, is less than $3 \mathrm{~m} / \mathrm{s}$. The average wind velocity for analyzed area is below the minimum velocity needed for wind-electric generation.

\section{REFERENCES}

[1] Global energy and $\mathrm{CO}_{2}$ status report 2019, International Energy Agency. See https://www.iea.org/reports/globalenergy-co2-status-report-2019

[2] Carneiro, F. M., Rocha, H. B., \& Rocha, P. C. (2013). Investigation of Possible Societal Risk Associated with Wind Power Generation Systems. Renewable and Sustainable Energy Reviews, 19, 30-36. https://doi.org/10.1016/j.rser.2012.11.006

[3] Mathew, S., Pandey, K., \& Kumar, V. A. (2002). Analysis of Wind Regimes for Energy Estimation. Renewable Energy, 25(3), 381-399. https://doi.org/10.1016/S0960-1481(01)00063-5

[4] Dahbi, M., Benatiallah, A., \& Sellam, M. (2013). The Analysis of Wind Power Potential in Sahara Site of Algeria- an Estimation Using the Weibull Density Function. Energy Procedia, 36, 179 -188. https://doi.org/10.1016/j.egypro.2013.07.021

[5] Bataineh, K. M. \& Dalalah, D. (2013). Assessment of wind energy potential for selected areas in Jordan. Renewable Energy, 59, 75-81. https://doi.org/10.1016/j.renene.2013.03.034

[6] Safari, B. \& Gasore, J. (2010). A statistical investigation of wind characteristics and wind energy potential based on the Weibull and Rayleigh models in Rwanda. Renewable Energy, 35(12), 2874-2880. https://doi.org/10.1016/j.renene.2010.04.032

[7] Mahmood, F. H., Resen, A. K., \& Khamees, A. B. (2020). Wind characteristic analysis based on Weibull distribution of Al-Salman site, Iraq. Energy Reports, 6, 79-87. https://doi.org/10.1016/j.egyr.2019.10.021

[8] Lalas, D. P., Tselepidaki, H., \& Theoharatos, G. (1983). An analysis of wind potential in Greece. Solar Energy, 30(6), 497-505. https://doi.org/10.1016/0038-092X(83)90061-0

[9] Gökçek, M., Bayülken, A., \& Bekdemir, Ş. (2007). Investigation of wind characteristics and wind energy potential in Kirklareli, Turkey. Journal of Renewable Energy, 32(10), 1739-1752. https://doi.org/10.1016/j.renene.2006.11.017

[10] Vogiatzis, N., Kotti, K., Spanomitsios, S., \& Stoukides, M. (2004). Analysis of wind potential and characteristics in North Aegean, Greece. Renewable Energy, 29(7), 11931208. https://doi.org/10.1016/j.renene.2003.11.017

[11] Ucar, A. \& Balo, F. (2009). Investigation of wind characteristics and assessment of wind generation potentiality in Uludag-Bursa, Turkey. Applied Energy, 86(3), 333-339. https://doi.org/10.1016/j.apenergy.2008.05.001

[12] Al-Buhairi, M. H. \& Al-Haydari, A. (2012). Monthly and Seasonal Investigation of Wind Characteristics and Assessment of Wind Energy Potential in Al-Mokha, Yemen. Energy and Power Engineering, 04(03), 125-131.

https:// doi.org/10.4236/epe.2012.43017

[13] Akpinar, E. K. \&Akpinar, S. (2004). Statistical analysis of wind energy potential on the basis of the Weibull and Rayleigh distributions for Agin-Elazig, Turkey. Proceedings of the Institution of Mechanical Engineers, Part A: Journal of Power and Energy, 218(8), 557-565. https://doi.org/10.1243/0957650042584357

[14] Celik, A. N. (2004). A statistical analysis of wind power density based on the Weibull and Rayleigh models at the southern region of Turkey. Renewable Energy, 29(4), 593604. https://doi.org/10.1016/j.renene.2003.07.002

[15] Azad, A. K., Rasul, M. G., Alam, M. M., Uddin, S. M., \& Mondal, S. K. (2014). Assessment of wind energy potential by Weibull distribution in isolated islands. Proceedings of the $3^{\text {rd }}$ International Conference on the Developments in Renewable Energy Technology (ICDRET). https://doi.org/10.1109/icdret.2014.6861732

[16] Alam, M. M. \& Azad, A. K. (2009). Analysis of Weibull Parameters for the Three Most Prospective Wind Sites of Bangladesh. Proceedings of the International Conference on Mechanical Engineering (ICME09-FM-07).

[17] Azad, A. K. \& Saha, M. (2011). Weibull's Analysis of Wind Power Potential at Coastal Sites in Kuakata, Bangladesh. International Journal of Energy Machinery, 4(1), 36-45.

[18] Fyrippis, I., Axaopoulos, P. J., \& Panayiotou, G. (2010). Wind energy potential assessment in Naxos Island, Greece. Applied Energy, 87(2), 577-586. https://doi.org/10.1016/j.apenergy.2009.05.031

[19] Stevens, M. \& Smulders, P. (1979). The estimation of the parameters of the Weibull wind speed distribution for wind energy utilization purposes. Wind Engineering, 3(2), 132145

[20] Akdağ, S. A. \& Dinler, A. (2009). A New Method to Estimate Weibull Parameters for Wind Energy Applications. 
Energy Conversion and Management, 50(7), 1761-1766. https://doi.org/10.1016/j.enconman.2009.03.020

[21] Kang, D., Ko, K., \& Huh, J. (2018). Comparative Study of Different Methods for Estimating Weibull Parameters: A Case Study on Jeju Island, South Korea. Energies, 11(2), 356. https://doi.org/10.3390/en11020356

[22] Seguro, J. \& Lambert, T. (2000). Modern estimation of the parameters of the Weibull wind speed distribution for wind energy analysis. Journal of Wind Engineering and Industrial Aerodynamics, 85(1), 75-84. https://doi.org/10.1016/S0167-6105(99)00122-1

[23] Rocha, P. A., Sousa, R. C., Andrade, C. F., \& Silva, M. E. (2012). Comparison of seven numerical methods for determining Weibull parameters for wind energy generation in the northeast region of Brazil. Applied Energy, 8(1), 395400. https://doi.org/10.1016/j.apenergy.2011.08.003

[24] Parajuli, A. (2016). A statistical analysis of wind speed and power density based on Weibull and Rayleigh models of Jumla, Nepal. Energy and Power Engineering, 8(7), 271282. https://doi.org/10.4236/epe.2016.87026

[25] Azad, A., Rasul, M., Alam, M., Uddin, S. A., \& Mondal, S. K. (2014). Analysis of wind energy conversion system using Weibull distribution. Procedia Engineering, 90, 725-732. https://doi.org/10.1016/j.proeng.2014.11.803

[26] Azad, A., Rasul, M., Islam, R., \& Shishir, I. R. (2015). Analysis of wind energy prospect for power generation by three Weibull distribution methods. Energy Procedia, 75, 722-727. https://doi.org/10.1016/j.egypro.2015.07.499

[27] Usta, I. (2016). An innovative estimation method regarding Weibull parameters for wind energy applications. Energy, 106, 301-314. https://doi.org/10.1016/j.energy.2016.03.068

[28] Mert, I. \& Karakuş, C. (2015). A statistical analysis of wind speed data using Burr, generalized gamma, and Weibull distributions in Antakya. Turkish Journal of Electrical Engineering \& Computer Sciences, 23, 1571-1586. https://doi.org/10.3906/elk-1402-66

[29] Satwika, N. A., Hantoro, R., Septyaningrum, E., \& Mahmashani, A. W. (2019). Analysis of wind energy potential and wind energy development to evaluate performance of wind turbine installation in Bali, Indonesia. Journal of Mechanical Engineering and Sciences, 13(1), 4461-4476. https://doi.org/10.15282/jmes.13.1.2019.09.0379

[30] Yilmaz, V. \& Celik, H. E. (2008). A statistical approach to estimate the wind speed distribution: the case of Gelibolu region. Doğuş Üniversitesi Dergisi, 1(9), 122-132. https://doi.org/10.31671/dogus.2019.227

[31] Hadziahmetovic, H., Dzaferovic, E., Ahmovic, I., \& Blazevic, R. (2018). Analysis of Wind Velocity Data in the Area of the City of Sarajevo in Period from 2001-2010. Proceedings of the 29th International DAAAM Symposium 2018, DAAAM Proceedings, 0250-0259. https://doi.org/10.2507/29th.daaam.proceedings.036

[32] Hadziahmetovic, H., Ahmovic, I., \& Blazevic, R. (2019). Analysis of Wind Velocity Data in the Area of the City of Sarajevo in Period from 1980-1990, Proceedings of the $30^{\text {th }}$ International DAAAM Symposium 2019, DAAAM Proceedings, 0240-0247. https://doi.org/10.2507/30th.daaam.proceedings.031

[33] Hensen, J. L. M. (1999). Simulation of building energy and indoor environmental quality-some weather data issues. Proceedings of the International Workshop on Climate data and their applications in engineering, 4-6.

[34] Ouammi, A., Dagdougui, H., Sacile, R., \& Mimet, A. (2010). Monthly and seasonal assessment of wind energy characteristics at four monitored locations in Liguria region (Italy). Renewable and Sustainable Energy Reviews, 14(7), 1959-1968. https://doi.org/10.1016/j.rser.2010.04.015

[35] Syngellakis, K. \& Traylor, H. (2007). Urban Wind resource assessment in the UK: An introduction to wind resource assessment in the urban environment, Reports No. 2,
European Commission. Retrieved from http://www.urbanwind.org/pdf/Reports_UrbanWindResourceAssessment_U K.pdf

\section{Contact information:}

Rejhana BLAŽEVIĆ, dr. sc. Assistant Professor

(Corresponding author)

University of Sarajevo,

Faculty of Mechanical Engineering Sarajevo,

Vilsonovo šetalište 9, 71000 Sarajevo, Bosnia \& Herzegovina

E-mail: muhamedagic@mef.unsa.ba

Halima HADŽıAHMETOVIĆ, dr. sc. Associate Professor

University of Sarajevo,

Faculty of Mechanical Engineering Sarajevo,

Vilsonovo šetalište 9, 71000 Sarajevo, Bosnia \& Herzegovina

E-mail: halima@mef.unsa.ba

Ismira AHMOVIĆ, Researcher

Federal Hydrometeorological Institute of Bosnia \& Herzegovina,

Bardakčije 12, 71000 Sarajevo, Bosnia \& Herzegovina

E-mail: ismiraahmovic@yahoo.com 